Fifth International Conference on Sustainable Construction Materials and Technologies. http://www.claisse.info/Proceedings.htm

\title{
INFLUENCE OF PLASTIC RECYCLED AGGREGATES IN THE HARDENED PROPERTIES OF CONCRETES
}

\author{
E. Hernández ${ }^{a}$, M. Etxeberria ${ }^{b^{*}}$ \\ ${ }^{a}$ Graduate School of architecture, National Autonomous University of Mexico. \\ ${ }^{\mathrm{b}}$ Department of civil engineering, University Polytechnic of Catalonia.
}

\begin{abstract}
The use of the new resource of man-made plastic aggregates as an alternative to natural aggregate could be a viable answer for developing new construction material. Not only would we eliminate a harmful waste but also preserve natural resources from overexploitation. This paper deals with the production and analysis of the properties of concretes employing recycled plastic (being high-density polyethene) aggregates in replacement of up to $75 \%$ of natural aggregates. The analysis of the concrete properties was undertaken in the fresh state and hardened state after 28 days of curing. The results revealed that the employment of a higher percentage of plastic particles in substitution for natural aggregates resulted in a decrease in the density of concrete as well as its thermal conductivity. The compressive strength of concretes also decreased; however, the toughness of the recycled plastic aggregates concretes increased with respet to that of conventional concrete.
\end{abstract}

Keywords: Aggregates, concrete, plastics, recycled.

\section{INTRODUCTION}

As the world's population grows, plastic consumption increases due to rapid urbanisation and economic development (Alqahtani et al., 2017). Nonetheless, plastics are nondegradable and generally take a long time to break down, possibly up to hundreds of years. Moreover, increasing their production also increases the required landfill space for plastic waste, which significantly contributes to their environmental impact (Siddique, Khatib and Kaur, 2008). The reduction of plastic wastes to protect the environment is crucial. The most sensible solution is to replace significant portions of the aggregates in concrete with recycled plastic wastes as an alternative aggregate while maintaining some of its mechanical properties (Siddique, Khatib and Kaur, 2008; Hannawi, Kamali-Bernard and Prince, 2010; Alqahtani et al., 2018). 
The research work carried out by Naik et al. (Naik et al., 1996) was one of the first papers promoting the use of recycled high-density polyethene (HDPE) aggregates in replacement of raw aggregates in concrete production. The plastic aggregate concrete achieved similar properties to conventional concretes, as a low percentage of substitution of raw aggregates (up to 5\%) was employed. However, it was concluded that there was a need for an improvement in the bond between the plastic aggregates and cement paste in order to improve the properties of plastic aggregate concretes. Several researchers (Dalal, 1997; Albano et al., 2009) analysed the influence of HDPE aggregates in different concrete properties. They concluded that it not only reduced the density and compressive strength, but also led to a considerable increase in the ductility of the concretes.

The main findings of the research studies (Albano et al., 2009; Rai et al., 2012) conducted on concrete containing shredded or plastic aggregate particles indicate that the concrete workability, density and mechanical properties; such as compressive strength, splitting tensile strength, flexural strength and modulus of elasticity; significantly decrease with the increase in plastic content. However, the toughness increased in concretes produced employing plastic aggregates (Saikia and De Brito, 2012). The density of concrete and cement mortar was reduced by 7 to $50 \%$ due to the increase in the ratio of plastic particles from 20 to 100\% (Tang, Lo and Nadeem, 2008; Hannawi, Kamali-Bernard and Prince, 2010).

In this paper the plastic high-density polyethylene (HDPE) coarse aggregates used in concrete production were obtained via the crushing of post-consumer plastic for packing and containers. Physical and mechanical properties of the concretes produced using different percentages $(25 \%, 50 \%$ and $75 \%$ in volume) of plastic aggregates in substitution of natural aggregates were assessed. The obtained results of the plastic aggregate concretes were compared to the results of conventional concrete.

\section{MATERIALS AND EXPERIMENTAL METHOD}

\subsection{Materials}

\subsubsection{Binder and Admixture}

Type CEM II/A-L 42.5 N, normal strength Portland cement with $20 \%$ filler was used in all concrete production. Limestone filler was also used in concrete production in order to increase the consistency and compactness of the cement paste. A superplasticizer with a base of modified polycarboxylate-ether (PCE) and a specific gravity of 1.08 was also employed.

\subsubsection{Natural Aggregates}

Two fractions of crushed limestone aggregates (fine $0-4 \mathrm{~mm}$ and coarse $4-10 \mathrm{~mm}$ aggregates) were employed for concrete production. Figure 1 shows the particle grading distributions of the natural aggregates, which were determined following BS-EN 9331:2012 standards. 
The dry density of the fine and coarse aggregates were 2.57 and $2.59 \mathrm{~kg} / \mathrm{dm}^{3}$, respectively. The water absorption of the fine and coarse aggregates was 1.7 and $0.87 \mathrm{~kg} / \mathrm{dm}^{3}$, respectively. Both properties were determined following BS-EN 1097-6:2013 specifications.

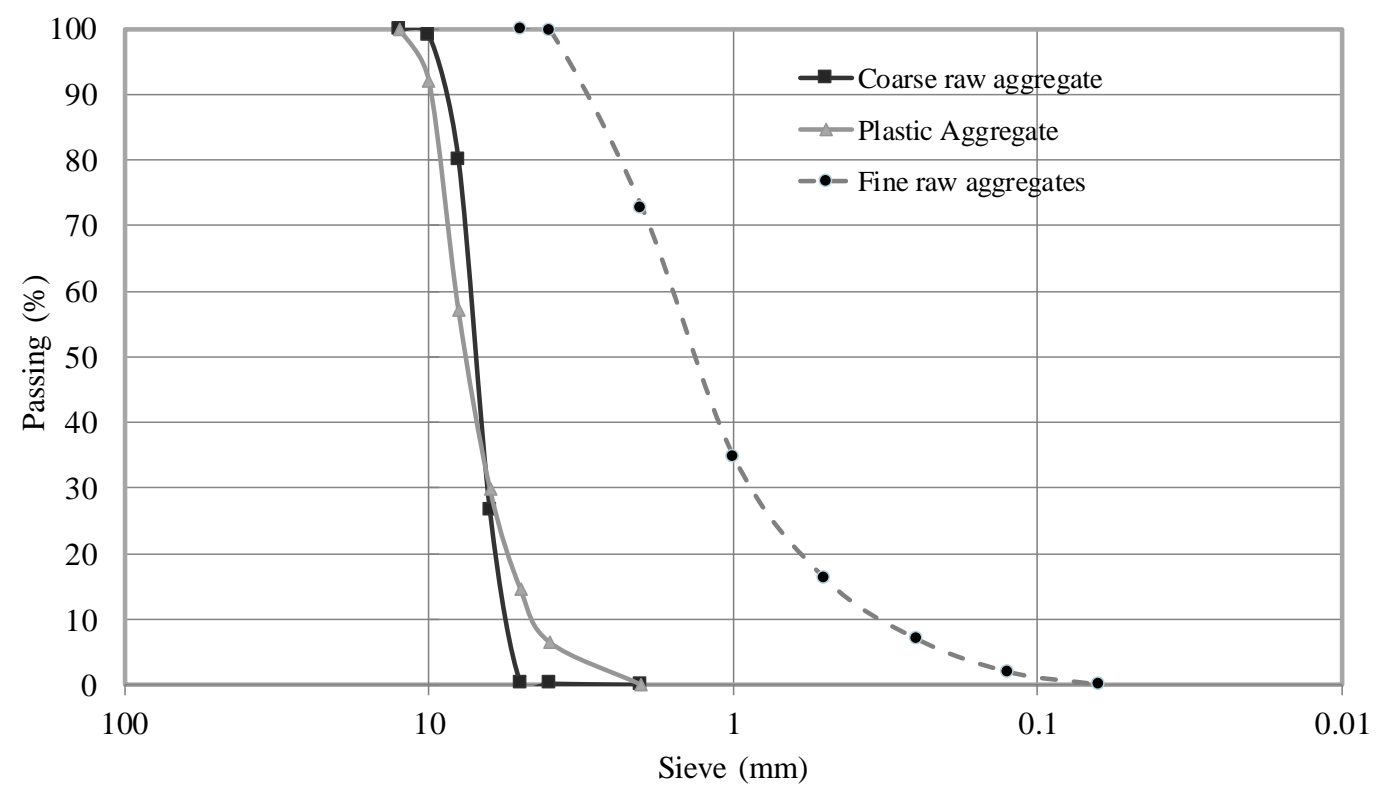

Figure 1. Grading distribution of natural and plastic aggregates

\subsubsection{Plastic Aggregates}

A high-density polyethylene HDPE plastic aggregate was employed in partial replacement of natural coarse aggregates for concrete production. The plastic aggregates were obtained from the recycling of plastic fruit or vegetable mesh crates. They were first submitted to the primary process of cutting and then later to crushing to achieve the pellet form. The Plastic1 (P1) with 4/10 mm fraction was multicolour (see figure 2) and had a density of $0.96 \mathrm{~kg} / \mathrm{dm}^{3}$, its grading distribution is shown in Figure 1.

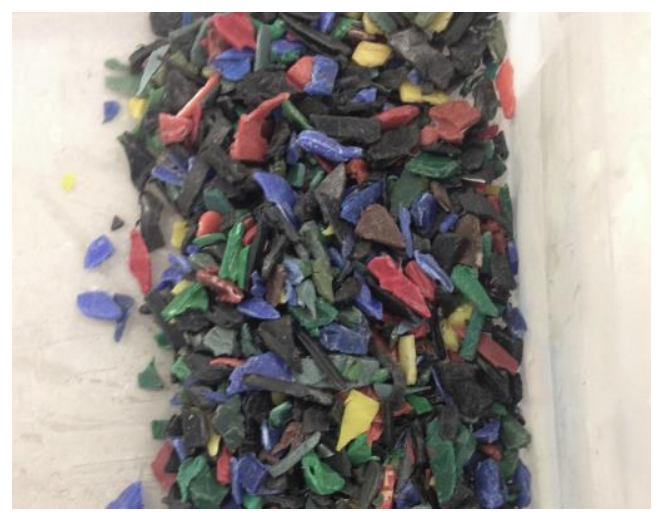


Figure 2. The appearance of plastic aggregate

\subsection{Concrete Mixtures}

Table 1 shows the mix proportion of the concretes produced and analysed in this research work. The mix proportion of the conventional concrete was defined according to the maximum compactness of natural aggregates. Two series of concretes were produced taking into account the cementitious material (cement + filler) amount and water-cement ratio. In series 1 (s1), $275 \mathrm{~kg}$ of cement and $55 \mathrm{~kg}$ of limestone filler were employed as the binder. A water-cement ratio of 0.65 was also used for concrete production. In series 2 (s2), $350 \mathrm{~kg}$ of cement with $50 \mathrm{~kg}$ of limestone filler were employed as the binder, and a water-cement ratio of 0.55 was used for the production of all concretes.

In both series a conventional concrete (CC-s1 and CC-s2) and concretes employing $25 \%$, $50 \%$ and $75 \%$ of plastic aggregates in replacement (in volume) of natural aggregates were produced. The obtained results of each of the recycled concretes were compared to those obtained from the conventional concrete (concretes produced with natural aggregates).

Tabla 1. Mix proportions of the produced concretes. It is given the $\mathrm{kg}$ of each component of the production of $1 \mathrm{~m} 3$ of concrete

\begin{tabular}{|c|c|c|c|c|c|c|c|c|}
\hline Concrete & Cement & Sand & Filler & Gravel & Plastic & Water & $\begin{array}{c}\text { Admixture } \\
(\%)\end{array}$ & $\begin{array}{l}\text { Density } \\
\left(\mathbf{k g} / \mathbf{d m}^{3}\right)\end{array}$ \\
\hline CC-s1 & 275 & 887.5 & 55 & 894.4 & - & 198 & 0.25 & 2,36 \\
\hline CP1-25-s1 & 275 & 887.5 & 55 & 670.8 & 82.9 & 198 & 0.13 & 2,21 \\
\hline CP1-50-s1 & 275 & 887.5 & 55 & 447.2 & 165.8 & 198 & 0.42 & 2,09 \\
\hline CP1-75-s1 & 275 & 887.5 & 55 & 223.6 & 248.6 & 198 & 0.53 & 2,01 \\
\hline CC-s2 & 350 & 855.8 & 50 & 862.4 & - & 198 & 0.41 & 2.45 \\
\hline CP1-25-s2 & 350 & 855.8 & 50 & 646.9 & 79.9 & 200 & 0.21 & 2,25 \\
\hline CP1-50-s2 & 350 & 855.8 & 50 & 431.4 & 159.8 & 200 & 0.48 & 2,13 \\
\hline CP1-75-s2 & 350 & 855.8 & 50 & 215.6 & 239.8 & 200 & 0.59 & 2,05 \\
\hline
\end{tabular}

At fresh state, temperature and consistency of all the concretes were determined following UNE-EN 12350-2:2009 specifications. All concretes achieved a temperature value of $21 \pm 1{ }^{\circ} \mathrm{C}$ as well as the slump test value of $70 \mathrm{~mm} \pm 10 \mathrm{~mm}$. The density values obtained by all of the concretes are shown in Table 1 .

The concrete specimens were compacted manually. They were covered with a plastic sheet and air-cured for the first 24 hours. After that period, the concrete specimens were demoulded and stored in a humidity room (at $21^{\circ} \mathrm{C}$ and $95 \%$ humidity) until the test ages were reached. 


\subsection{Tests Procedure for Hardened State Properties}

\subsubsection{Physical Properties}

The density, absorption and voids of all the produced concretes were determined at 28 days after casting, following ASTM C 642 specification. In addition, the thermal conductivity of the concretes was measured according to BS-EN 1745. Three cubic specimens were employed to determine each of the properties.

\subsubsection{Mechanical Properties}

The compressive, tensile splitting strength, flexural strengths and modulus of elasticity were determined in all the concretes. In addition, the strength-strain behaviour of all the concretes, including their toughness was assessed. The compressive strength was measured at the ages of 7 and 28 days following BS-EN 12390-3:2009 specifications. Three $100 \mathrm{~mm}$ cubic specimens were used for each testing age. The splitting tensile strength, flexural strength and modulus of elasticity were determined after 28 days of casting, following BS-EN 12390-6:2009, BS-EN 12390-6:2010 and BS-EN 1239013:2014 specifications, respectively. The splitting tensile strength and modulus elasticity were determined via the testing of three cylindrical core specimens $\varnothing 100 \times 200 \mathrm{~mm}$ for each property. The flexural strength was determined via the measurement of three prismatic laboratory specimens of $100 \times 100 \times 400$, and the strength-strain curve behaviour of the concretes was determined by employing cylindrical specimens.

All the mechanical properties were determined via the employment of a compressive loading machine of $3000 \mathrm{kN}$.

\section{RESULTS AND DISCUSSION}

\subsection{Physical Properties}

An increase in the replacement of raw aggregates for plastic aggregates led to a decrease in the density of the concretes, as table 3 shows, this was due in turn to the low density of the plastic aggregates. When more than $25 \%$ of plastic aggregates were employed for concrete production, a density value lower than that of $2 \mathrm{~kg} / \mathrm{dm}^{3}$ was achieved. Thus considering it to be a lightweight concrete.

Table 2. Physical properties of concretes

\begin{tabular}{|c|c|c|c|c|c|c|}
\hline & \multicolumn{2}{|c|}{ Dry density $(\mathrm{kg} / \mathrm{m} 3)$} & \multicolumn{2}{|c|}{ Absorption (\%) } & \multicolumn{2}{|c|}{$\begin{array}{l}\text { Thermal Conductivity } \\
\text { (W/m.K) }\end{array}$} \\
\hline & \begin{tabular}{|l|} 
Serie1 \\
(s1)
\end{tabular} & \begin{tabular}{|l} 
serie2 \\
$(\mathrm{s} 2)$
\end{tabular} & \begin{tabular}{|l} 
serie1 \\
(s1)
\end{tabular} & $\begin{array}{l}\text { serie2 } \\
(\mathrm{s} 2)\end{array}$ & \begin{tabular}{|l} 
serie1 \\
(s1)
\end{tabular} & serie2 $(\mathrm{s} 2)$ \\
\hline $\mathrm{CC}$ & 2,32 & 2,29 & 2,67 & 2,36 & 1,74 & 1,6 \\
\hline CP1-25 & 2,09 & 2,12 & 3,35 & 3,09 & 1,39 & 1,42 \\
\hline CP1-50 & 1,93 & 2 & 3,57 & 4,02 & 1,07 & 1,09 \\
\hline
\end{tabular}




\begin{tabular}{|l|r|r|r|r|r|r|}
$\mathrm{CP} 1-75$ & 1,8 & 1,8 & 4,31 & 4,79 & 0,86 & 1,03 \\
\hline
\end{tabular}

The water absorption capacity of both series 1 and 2 concretes increased when a higher percentage of plastic aggregates were employed, resulting in both achieving similar values.

According to the Mexican standard NOM-020-ENER-2011 (Ley, 2012), the thermal conductivity value of conventional concrete is approximate of $1.74-1.6 \mathrm{~W} / \mathrm{m}$. K. Table 2 shows that $\mathrm{CC}$ concrete of series 1 and 2 achieved these standard results. In addition, the employment of plastic aggregates reduced the thermal conductivity of concretes considerably, as proved by other researchers (Saikia and De Brito, 2012; Akçaözoğlu, Akçaözoğlu and Atiş, 2013; Coppola et al., 2018) .

The CC concrete produced in series 2 achieved the lower conductivity than that of CC concrete in Series 1, this in all probability being due to firstly, the lower volume of natural aggregates and secondly, the concrete being more compacted than that of the $\mathrm{CC}$ series 1 . However, when plastic aggregates were used, the concretes produced in series 1 and series 2 achieved similar values, as previously explain when considering the absorption values. The concretes produced with $75 \%$ of plastic aggregates reduced the thermal conductivity by up to $35 \%$ with respect to the value obtained by CC concretes. The appearance of plastic aggregate concrete is illustrated in figure 3.
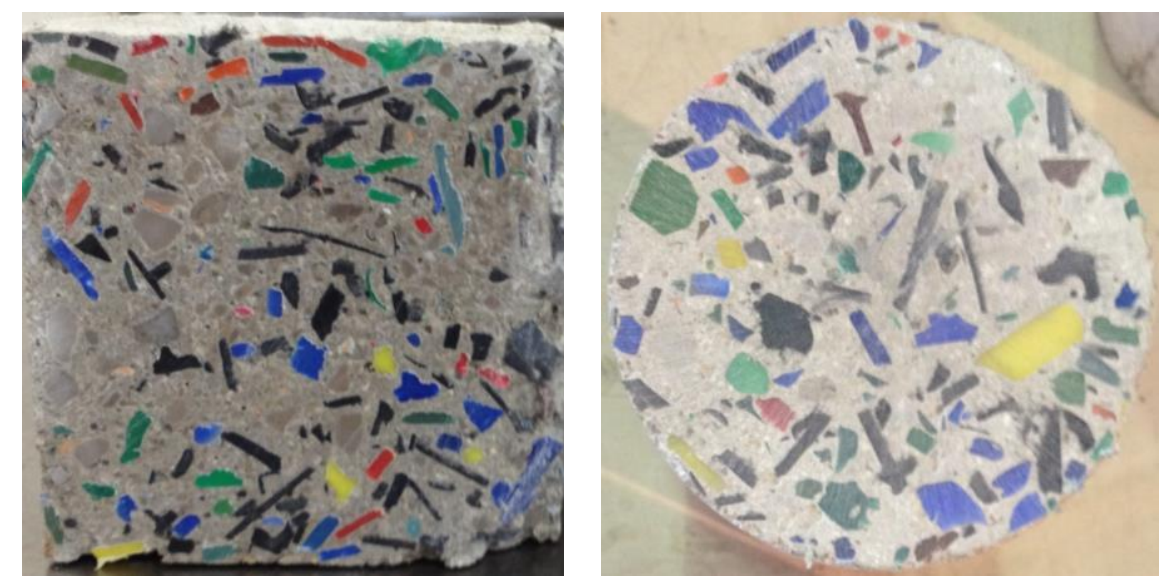

Figure 3. appearance of concree

\subsection{Mechanical Properties.}

Table 3 shows the mechanical properties obtained by all the concretes studied. Both CC1 and CC- 2 conventional concretes (from series 1 and series 2, respectively) were defined as structural concretes.

It was found that when compared to the properties obtained of $\mathrm{CC}$ concrete the concrete employing plastic aggregates led to a reduction in the mechanical properties of those concretes. Although the increase of compression strength from 7 to 28 days was similar in all the concretes, the influence of plastic aggregates was higher in the series 2 concretes 
(concretes produced employing lower water-cement ratio). It is clearly shown in Figure $4 \mathrm{a}$, that the concrete produced in series 1 achieved a lower decrease of compressive strength with respect to CC concrete than those in series 2.

The concrete produced employing $25 \%$ of the plastic aggregates in series 11 (s1) achieved a higher compressive and flexural strength than that of CC-s1. The CP1-25-s1 achieved $8 \%$ higher compressive strength than the CC-s1 concrete.

Table. 3 Results in mechanical properties

\begin{tabular}{|c|c|c|c|c|c|}
\hline Concrete & \multicolumn{2}{|c|}{$\begin{array}{c}\text { Compressive Strenght } \\
\text { (MPa) }\end{array}$} & $\begin{array}{c}\text { Splitting } \\
\text { Tensile(MPa) }\end{array}$ & $\begin{array}{c}\text { Flexural } \\
\text { strength } \\
\text { (MPa) }\end{array}$ & $\begin{array}{c}\text { Young } \\
\text { Modulus } \\
\text { (GPa) }\end{array}$ \\
\hline type & 7 days & 28 days & 28 days & 28 days & 28 days \\
\hline CC-s1 & 25,81 & 27,70 & 2,60 & 4,29 & 29,11 \\
\hline CP1-25-s1 & 26,17 & 29,91 & 2,17 & 4,35 & 21,91 \\
\hline CP1-50-s1 & 20,61 & 22,68 & 1,99 & 3,35 & 13,17 \\
\hline CP1-75-s1 & 16,81 & 18,33 & 1,79 & 3,38 & 9,73 \\
\hline CC-s2 & 41,84 & 44,17 & 2,98 & 4,55 & 33,75 \\
\hline CP1-25-s2 & 31,42 & 34,74 & 2,73 & 4,22 & 27,20 \\
\hline CP1-50-s2 & 25,76 & 27,99 & 2,11 & 3,73 & 16,12 \\
\hline CP1-75-s2 & 22,40 & 23,23 & 1,92 & $/$ & 12,89 \\
\hline
\end{tabular}

According to Spanish structural concrete standard (EHE-08, 2010) a minimum of $20 \mathrm{MPa}$ is required for plain structural concrete. All the concretes produced in series 2 achieved the minimum requirements. In series 1 , the concretes produced employing up to $50 \%$ of plastic aggregates in replacement to raw aggregates were defined as being adequate.

The splitting tensile strength of concretes produced employing plastic aggregates (see Figure 4b) was lower than that of conventional concretes. The concretes produced using $25 \%$ of plastic aggregates in replacement of natural aggregates were the only concretes which achieved a decrease lower than $10 \%$ with respect to that of CC concrete.

It is known, the quality of the ITZ has an influence on the splitting tensile strength of concretes (Hannawi, Kamali-Bernard and Prince, 2010), due to the hydrophobic effect on the plastic surfaces. 


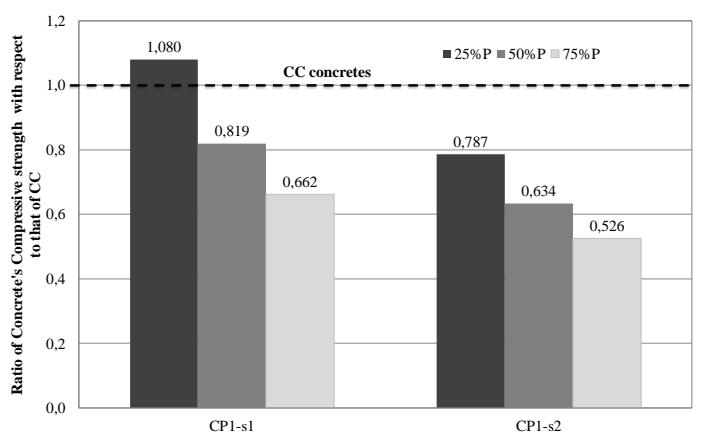

(a)

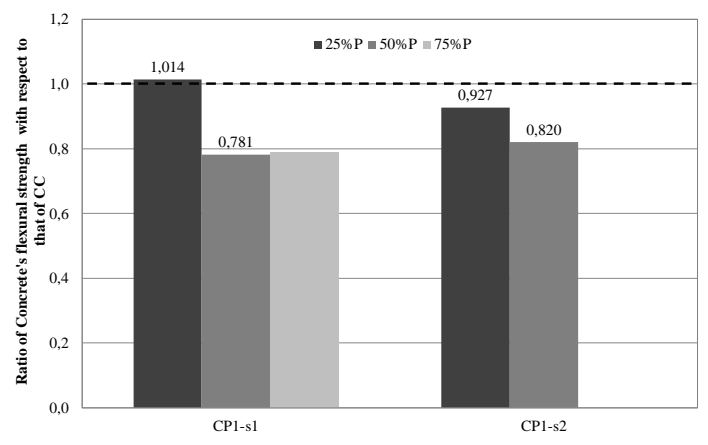

(c)

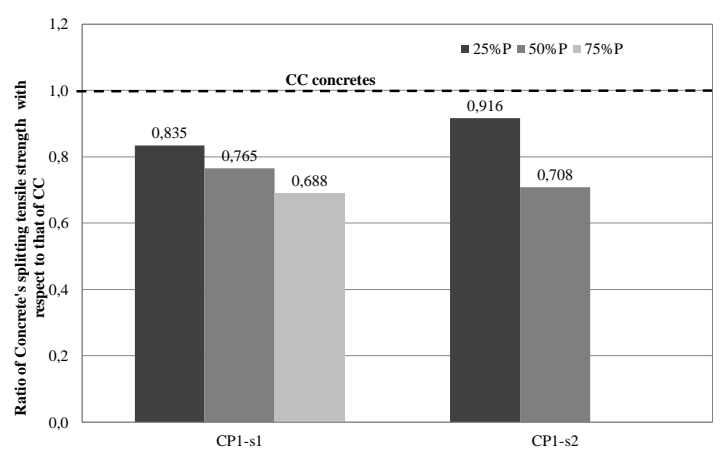

(b)

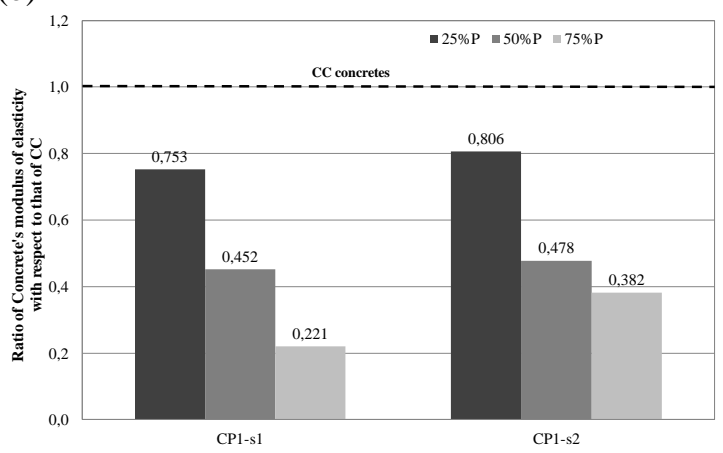

(d)

Fig. 4 The ratio of mechanical properties of concretes produced employing plastic aggregates with respect to those of conventional concretes. (a) Compressive strength; (b) Splitting tensile strength; (c) Flexural strength; (d) Modulus of elasticity.

Figure 4c illustrates the flexural strength value of plastic aggregate concretes with respect to those of $\mathrm{CC}$ concretes. The plastic aggregate concretes produced employing up to $50 \%$ of plastic aggregates in series 2, achieved similar properties to those of CC concrete, the obtained values being higher than $4 \mathrm{MPa}$. This mechanical property was shown to be the least affected by the substitution of plastic aggregates with respect to CC concrete. In all probability due to the increase of ductility of the concretes produced employing plastic aggregates (Saikia and De Brito, 2012; Saikia and Brito, 2013).

The values of modulus elasticity of each type of concrete is described in Table 3 . The modulus of elasticity of the plastic aggregate concretes were lower than that of $\mathrm{CC}$ concretes, as defined by seral researchers (Siddique, Khatib and Kaur, 2008; Hannawi, Kamali-Bernard and Prince, 2010; Saikia and De Brito, 2012). In addition, the decrease of the modulus was higher when a higher percentage of plastic aggregates were used (see 
Figure 4d). The use of plastic aggregates greatly influenced the modulus elasticity of the mechanical properties, due to their high deformability capacity. It is known that the modulus of elasticity of concrete depends strongly by the modulus elasticity and density of aggregates (Lydon and Balendran, 1986).

Figure 5 shows the strength-strain curves of all the plastic aggregate concretes produced in series 1 and series 2. It is noted that the employment of plastic aggregates for concrete production reduced their compressive strength, however the strain capacity of the concrete was increased, thus augmenting the toughness of those concretes, as several research demonstrated (Ferreira, De Brito and Saikia, 2012; Saikia and De Brito, 2012; JacobVaillancourt and Sorelli, 2018). The toughness value was determined, according to the method used by G. Giaccio et al. (Giaccio, Martín and Zerbino, 2001), calculating the area below the curve of each concrete from zero strain to the strain at $80 \%$ of the maximum strength at the dencendend load, see figure 6.The toughness value of each of the concretes are described in table 4.

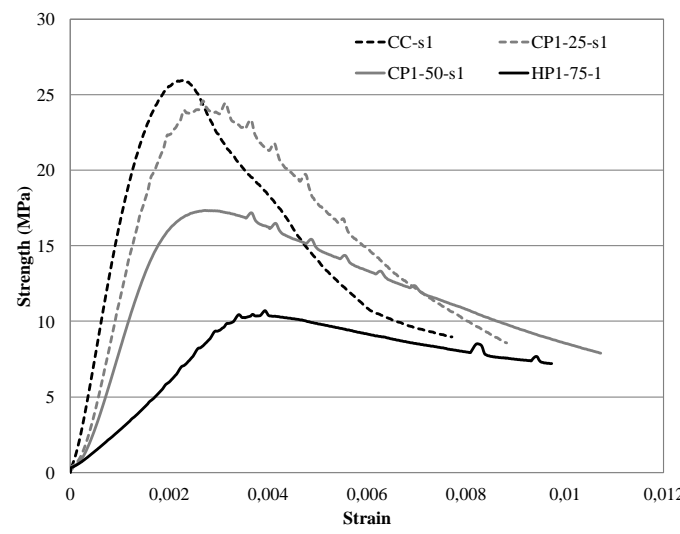

a)

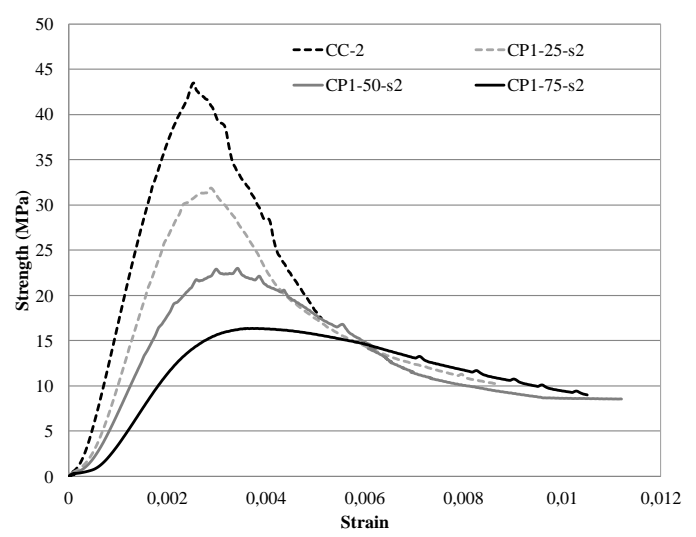

b)

Figure 5. Compressive strength-strain curves of all the concretes: a) series 1; b) series 2 


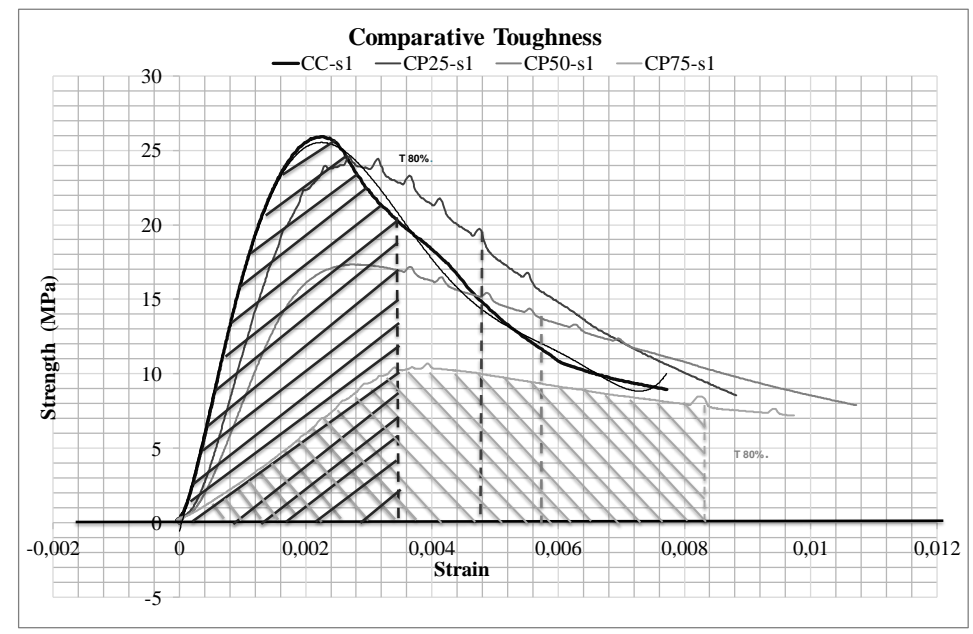

Figure 6. The toughness area of each of the concrete

The increase of the toughness value in series 1 occurred in concretes produced employing up to $50 \%$ of plastic aggregates. The use of a high percentage of plastic aggregates in concrete resulted in a less fragile material.

Table 4 shows the toughness

\begin{tabular}{|l|l|l|l|}
\hline \multicolumn{5}{|l|}{ Concrete } & $\begin{array}{l}\text { Toughness } \\
(\mathbf{M P a})\end{array}$ & Concrete & $\begin{array}{l}\text { Toughness } \\
\text { (MPa) }\end{array}$ \\
\hline CC-s1 & 0,061452 & CC-s2 & 0,087579 \\
\hline CP1-25-s1 & 0,083018 & CP1-25-2 & 0,073014 \\
\hline CP1-50-s1 & 0,075384 & CP1-50-s2 & 0,076974 \\
\hline CP1-75-s1 & 0,0618 & CP1-75-s2 & 0,083686 \\
\hline
\end{tabular}

\section{CONCLUSION}

The following conclusions can be made based on the results of this study:

The production process of concrete employing plastic aggregates was similar to that of conventional concrete.

Plastic aggregate concrete achieved lower density values than those of conventional concrete, thus making possible to produce lightweight concretes.

The thermal conductivity of plastic concrete increased considerably with respect to that of conventional concrete.

The physical properties of plastic aggregate concrete were very similar when they were produced employing a different water-cement ratio and cement amount. Consequenty 
plastic aggregates are a suitable substitute for natural aggregates in the production of lowmedium requirements concretes.

The mechanical properties of compressive strength, splitting tensile strength and modulus elasticity achieved lower values in concretes produced with plastic aggregates. However, the flexural strength of the concretes produced with $25 \%$ of plastic aggregates was higher than that of conventional concrete. In addition, the concrete produced employing $50 \%$ of plastic aggregates achieved less than a $20 \%$ lower reduction of flexural strength value with respect to $\mathrm{CC}$ concrete.

The plastic aggregates were found to increase the toughness value of the concrete. The concrete produced employing $75 \%$ of plastic aggregates achieved similar values to that of $\mathrm{CC}$ concrete. In addition, one could say that the plastic aggregates enhanced the concrete's appearance. Consequently enabling it to be an interesting material for construction elements in urban surroundings.

\section{REFERENCES}

Akçaözoğlu, S., Akçaözoğlu, K. and Atiş, C. D. (2013) 'Thermal conductivity, compressive strength and ultrasonic wave velocity of cementitious composite containing waste PET lightweight aggregate (WPLA)', Composites Part B: Engineering, 45(1), pp. 721-726. doi: 10.1016/j.compositesb.2012.09.012.

Albano, C. et al. (2009) 'Influence of content and particle size of waste pet bottles on concrete behavior at different w/c ratios', Waste Management. Elsevier Ltd, 29(10), pp. 2707-2716. doi: 10.1016/j.wasman.2009.05.007.

Alqahtani, F. K. et al. (2017) 'Novel lightweight concrete containing manufactured plastic aggregate', Construction and Building Materials. Elsevier Ltd, 148, pp. 386-397. doi: 10.1016/j.conbuildmat.2017.05.011.

Alqahtani, F. K. et al. (2018) 'Experimental study to investigate the engineering and durability performance of concrete using synthetic aggregates', Construction and Building Materials. Elsevier Ltd, 173, pp. 350-358. doi: 10.1016/j.conbuildmat.2018.04.018.

Coppola, B. et al. (2018) 'Hygro-thermal and durability properties of a lightweight mortar made with foamed plastic waste aggregates', Construction and Building Materials. Elsevier Ltd, 170, pp. 200-206. doi: 10.1016/j.conbuildmat.2018.03.083.

Dalal, A. A. A.-M. R. (1997) 'Concrete containing plastic aggregates', Concrete International, 19(8), pp. 47-52.

EHE-08 (2010) Code on structural concrete. Madrid, Spain: Centro de Publicaciones, 
Secretaría General Técnica, Ministerio de Fomento.

Ferreira, L., De Brito, J. and Saikia, N. (2012) 'Influence of curing conditions on the mechanical performance of concrete containing recycled plastic aggregate', Construction and Building Materials, 36, pp. 196-204. doi: 10.1016/j.conbuildmat.2012.02.098.

Giaccio, G., Martín, A. and Zerbino, R. (2001) 'Tenacidad en compresion en hormigones reforzados con fibras de acero', in Jornadas SAM - CONAMET - AAS 2001, pp. 913-918.

Hannawi, K., Kamali-Bernard, S. and Prince, W. (2010) 'Physical and mechanical properties of mortars containing PET and PC waste aggregates', Waste Management. Elsevier Ltd, 30(11), pp. 2312-2320. doi: 10.1016/j.wasman.2010.03.028.

Jacob-Vaillancourt, C. and Sorelli, L. (2018) 'Characterization of concrete composites with recycled plastic aggregates from postconsumer material streams', Construction and Building Materials. Elsevier Ltd, 182, pp. 561-572. doi: 10.1016/j.conbuildmat.2018.06.083.

Ley (2012) ‘Ley Federal sobre Metrología y Normalización LFMN’, pp. 1-49.

Lydon, F. . and Balendran, R. . (1986) 'Some observations on elastic properties of plain concrete', Cement and Concrete Research, 16(3), pp. 314-24.

Naik, T. R. et al. (1996) 'Use of post-consumer waste plastics in cement-based composites', Cement and Concrete Research, 26(10), pp. 1489-1492. doi: 10.1016/00088846(96)00135-4.

Rai, B. et al. (2012) 'Study of Waste Plastic Mix Concrete with Plasticizer', ISRN Civil Engineering, 2012, pp. 1-5. doi: 10.5402/2012/469272.

Saikia, N. and Brito, J. de (2013) 'Waste polyethylene terephthalate as an aggregate in concrete', Materials Research, 16(2), pp. 341-350. doi: 10.1590/S151614392013005000017.

Saikia, N. and De Brito, J. (2012) 'Use of plastic waste as aggregate in cement mortar and concrete preparation: A review', Construction and Building Materials. Elsevier Ltd, 34, pp. 385-401. doi: 10.1016/j.conbuildmat.2012.02.066.

Siddique, R., Khatib, J. and Kaur, I. (2008) 'Use of recycled plastic in concrete: A review', Waste Management, 28(10), pp. 1835-1852. doi: 10.1016/j.wasman.2007.09.011.

Tang, W. C., Lo, Y. and Nadeem, A. (2008) 'Mechanical and drying shrinkage properties of structural-graded polystyrene aggregate concrete', Cement and Concrete Composites, 
30(5), pp. 403-409. doi: 10.1016/j.cemconcomp.2008.01.002. 